London, W.1, from its present premises, and the staff now numbers 118, mainly engaged on clerical and secretarial duties. The Information and Research Department comprises four divisions, concerned with finance and office management, personnel management, marketing and sales management, and production management, and includes the reference library. As regards finance, Sir Charles estimated that the Institute would at the earliest possible date require an annual income of not less than $£ 100,000$ in order to free itself from government financial assistance. It is hoped by 1952 to secure a fully representative council in which all the originally nominated members would be replaced, unless re-elected individually for a further term, and that it would soon be possible for the council to reach decisions on the fundamental principles involved in implementing the recommendation of the Baillieu Report with regard to the establishment of the Institute as a professional body with defined grades of membership. The Institute has already taken over the functions of the British Management Council, and the agreement with the Institute of Industrial Administration is designed to lead to a complete merger at the end of three years. Good progress is being made in building up a comprehensive information service, and the education committee is reviewing the whole field of education for management. Discussions have already taken place with university authorities on the contribution which the universities could make in this field.

\section{Journal of the Science of Food and Agriculture}

ThE Society of Chemical Industry published in January the first number of a new monthly, the Journal of the Science of Food and Agriculture (1, No. $1 ; 1950.3 s$, or $30 s$. per year; to members, $8 s$.$) .$ This new publication relieves the Society from the difficulty of finding room in the Journal of the Society of Chemical Industry for the increasing number of papers on food and agriculture which have been competing for space. Messages of goodwill from the respective Government Ministers indicate the importance that is attached to these two fields of activity, and this receives further emphasis in an article by Viscount Bruce on the work of the United Nations Food and Agriculture Organisation. It is perhaps significant of the present trend of food research in Great Britain that out of the seven research papers published in this number, three deal with fruits, one with vegetables, one with cereals, and only two with animal products. Vitamin $\mathrm{C}$ figures in two papers : one from the Royal Forest Factory at Coleford gives an interesting account of ascorbic acid oxidase inhibitors in black currants, and the other from the Lyons Laboratories, London, and the Western Province Fruit Research Station, Dopartment of Agriculture, Union of South Africa, compares the vitamin-C content of English and South African cabbages. Two papers, from the Tyons Laboratories and from the Defence Research Laboratories, General Chemistry Section, Maribyrnong, Victoria, provide valuable analytical data on fruits and on elephantseal oil respectively. Three papers deal with general biochemical problems : prevention of staling in bread (Government Laboratory, London); the combination of sulphur dioxide with concentrated orange juice (Low Temperature Research Station, Cambridge) ; and the oxidation of fat in dehydrated herrings (Torry Research Station, Aberdeen). Readers will look forward to further numbers, which will furnish a balanced picture of food and agricultural research being undertaken by academic and industrial workers in Great Britain as well as in other parts of the Commonwealth.

\section{Industrial Postgraduate Course in Engineering}

A LEAFLET recently issued by the British ThomsonHouston Co., Ltd., reprints an article from $B T H$ Activities which describes the advanced engineering course instituted two years ago by the Company at the Rugby works. This is a course of advanced lectures in mathematical analysis applied to physical and engineering problems which is given to a group of graduate apprentices. The course comprises two lectures each week given in working hours, and associated with the lectures is an evening tutorial class of two hours duration. The general character of the course, which extends over two years, may be gauged from the following list of topics. First-year course: general revision; vector field theory; operational calculus; theory of elasticity. Secondyear course : differential equations ; complex variable theory ; determinants, matrices and tensors ; mathematical statistics; advanced dynamics. Normally some sixteen men are selected for the first-year course, and at the end of the first year a further selection of a smaller number is made from those who wish to proceed to the second year. The purpose of the course is to meet the need experienced by those engaged in advanced design and research for mathematical equipment beyond that provided by the undergraduate course at the university. The basic mathematical work occupies one of the weekly lectures, while the second lecture deals with a related practical problem. Each of the practical lectures is given by an engineer who is a specialist in the subject. This intimate contact of the course with actual engineering problems not only stimulates the interest of the students but also ensures its development to keep pace with advances in practice.

\section{Brotherton Collection, University of Leeds}

THe thirteenth annual report of the Brotherton Collection Committee covering the session 1947-48 (pp. 12 ; University of Leeds, 1949) gives the contents of the Collection on June 30, 1948, as 22,764 books, 15,615 pamphlets, 477 manuscripts, 4,105 deeds, 31,216 letters and 25 maps. Cataloguing of nineteenth-century English literature continued, and 1,558 slips were added to the catalogue. Work has been commenced on the compilation of a detailed list of notable people whose correspondence with Sir Edmund Gosse is preserved in the Collection. The first of three exhibitions in the main Brotherton Room traced the development of the art of book illustration from the fifteenth century to the work of modern illustrators, while a third exhibition traced the development of the art of printing from Gutenberg to the present day. An exhibition of more special interest covered recent publications of the North American university presses.

\section{Work of the British-Kenya Miocene Expedition during 1949}

THE work carried out in 1949 by the British-Kenya Miocene Expedition was financed by a grant from the Kenya Government and by funds made available by Mr. C. W. Boise for the purchase of a motor-boat to facilitate work on the islands in Lake Victoria. The activities during the season, which started in February, were completed at the end of November, 